\title{
Alexandre Dumas y Victor Hugo, Viaje de los textos y textos del viaje, sous la direction de Angels Santa et Francisco Lafarga
}

\section{Laurence Richer}

\section{(2) OpenEdition \\ Journals}

Édition électronique

URL : http://journals.openedition.org/studifrancesi/8978

DOI : 10.4000/studifrancesi.8978

ISSN : 2427-5856

Éditeur

Rosenberg \& Sellier

Édition imprimée

Date de publication : 1 octobre 2008

Pagination : 476

ISSN : 0039-2944

\section{Référence électronique}

Laurence Richer, «Alexandre Dumas y Victor Hugo, Viaje de los textos y textos del viaje, sous la direction de Angels Santa et Francisco Lafarga », Studi Francesi [En ligne], 155 (LII | II) | 2008, mis en ligne le 30 novembre 2015, consulté le 07 janvier 2021. URL : http://journals.openedition.org/studifrancesi/8978 ; DOI : https://doi.org/10.4000/studifrancesi.8978

Ce document a été généré automatiquement le 7 janvier 2021.

\section{cc) (†) $\odot$}

Studi Francesi è distribuita con Licenza Creative Commons Attribuzione - Non commerciale - Non opere derivate 4.0 Internazionale. 


\title{
Alexandre Dumas y Victor Hugo, Viaje de los textos y textos del viaje, sous la direction de Angels Santa et Francisco Lafarga
}

\author{
Laurence Richer
}

\section{RÉFÉRENCE}

Alexandre Dumas y Victor Hugo, Viaje de los textos y textos del viaje, sous la direction de Angels SANTA et Francisco LAFARGA, Ed. de la Universitat de Lleida, Pagès, 2007, pp. 736.

1 Les quarante-deux communications de ce recueil se répartissent à peu près également entre l'espagnol et le français. Cette recension se bornera à rendre compte des articles en français. Le recueil, comme le titre l'indique, comporte une dimension comparatiste et le «voyage des textes» analyse, entre autres, la réception d'Hernani dans son «pays» (Heinz-Peter ENDRESS, pp.51-62). Mais il suit essentiellement les voyages des deux écrivains.

2 L'approche privilégie bien sûr le voyage en Espagne, pour la plus grande satisfaction des lecteurs de Hugo. Son lien profond avec ce pays, forgé dans les souvenirs contrastés de l'enfance et de la guerre, a largement irrigué son écriture, comme le rappellent Georges ZaRAgoza (pp. 497-511) et Alain V ERJAT (pp. 723-734). Le voyage permet d'en approfondir certains aspects, entre l'imagerie romantique et la vision personnelle (Mercé BoIXAReu, pp. 273-283). Il est quête d'un patrimoine historique (Isabelle MORNAT, pp. 285-296), il permet tous les jeux de l'écriture: une légende tirée de Lewis s'entoure de références espagnoles (Jean-François GuÉRAUD, pp.513-519), le tas de pierres évoque aussi bien le Chaos que le Créateur (Claude FoucART, pp. 689-699). Nous suivons aussi Hugo dans ses autres voyages vers l'Est, rares, mais importants pour son oeuvre: la Belgique, entre réminiscences picturales et industrie (André BÉNIT, pp. 349-369), et, bien 
sûr, le Rhin (Encarnación MEDINA, pp. 671-688) qui permet le lien avec Dumas; pour les deux écrivains, le texte est en rapport avec l'image, mais, contrairement à Hugo, qui dessine lui-même, il s'agit pour Dumas d'illustrateurs extérieurs (Claude ScHopp, pp. 373-389).

3 Alors que Hugo s'est finalement peu déplacé, nous avons affaire avec Dumas à un grand voyageur, dont l'imagination voyage encore plus. Son œuvre fictionnelle conduit parfois aussi loin que les Antilles (Ana MONLEón, pp. 589-606), et le voyage peut même être la porte ouverte au surnaturel dans le récit (Elise RADIX, pp. 627-639). Entraîné par les stéréotypes du romanesque, Dumas rencontre des bandits partout (Vittorio FRIGERIO, pp. 555-572). Le romanesque rejoint ici une vision convenue du voyage en Espagne: la critique de l'auberge espagnole, que l'auteur ne manque pas de faire, se retrouve sous la plume de voyageurs français depuis le XVII ${ }^{e}$ siècle (Lola JIMENES, pp. 479-491). Pourtant Dumas, souvent escorté par d'autres voyageurs confirmés, comme Mérimée, est aussi quelqu'un qui sait observer en toute liberté (Clarisse REQUENA, pp. 429-456), ou même retourner l'observation amusée vers le voyageur lui-même (Jean-René AYmES, pp. 391-410).

4 C'est donc un recueil qui interroge aussi bien le genre du voyage que celui du roman. Ce que la critique grecque reproche aux romans populaires de Dumas (Théodore KATSIKAROS, pp. 223-233) complète toute une critique morale de l'écriture fictionnelle, qui n'en excepte pas les plus grands. Le thème choisi est aussi l'occasion de rappeler le fort lien qu'établit la pensée du XIX siècle entre le temps et l'espace: on peut parler aussi de voyages historiques (Angels SANTA, pp. 611-626). Il s'agit d'un ensemble riche, intéressant à lire, qui vaut aussi bien par des études précises que par des vues plus générales. 